\title{
ПОСЛЕОПЕРАЦИОННЫЕ СПАЙКИ БРЮШНОЙ ПОЛОСТИ: ПАТОФИЗИОЛОГИЯ И ПРОФИЛАКТИКА (ОБЗОР ЛИТЕРАТУРЫ)
}

\section{POSTOPERATIVE ABDOMINAL ADHESION: PATHOPHYSIOLOGY AND PREVENTION (REVIEW)}

\section{Magomedov \\ M. Imanaliev \\ M. Magomedov}

Summary. Peritoneal adhesions are an important clinical problem in gastrointestinal surgery. Peritoneal adhesions are the result of irritation of the peritoneum by infection or surgical trauma and can be considered as a pathological part of healing after any injury to the peritoneum, in particular due to abdominal surgery. The balance between fibrin deposition and degradation is critical in determining normal peritoneal healing or adhesion formation. Postoperative peritoneal adhesions are a major cause of morbidity, leading to multiple complications, many of which may occur several years after the initial surgical procedure. In addition to acute small bowel obstruction, peritoneal adhesions can cause pelvic or abdominal pain and infertility. In this paper, the authors reviewed the epidemiology, pathogenesis, and various preventive strategies for adhesion formation. Several prophylactic agents have been investigated against postoperative peritoneal adhesions. Their role is aimed at activating fibrinolysis, making it difficult for blood to clot, reducing the inflammatory response, inhibiting collagen synthesis, or creating a barrier between adjacent wound surfaces. Their results are promising, but most of them are controversial and are achieved mainly in the animal model. Until further results from future clinical trials are obtained, only careful surgery can be recommended to reduce unnecessary morbidity and mortality from these adverse effects of surgery. With the current state of knowledge, preclinical or clinical studies are still needed to evaluate the effectiveness of developing strategies for the prevention of postoperative peritoneal adhesions is discussed in this review.

Keywords: abdominal surgery, laparoscopy, complication, adhesiolysis, abdominal pain, adhesions.

\author{
Магомедов Мухума Магомедович \\ Д.м.н., профессор, Дагестанский государственный \\ медицинский университет \\ muxuma@mail.ru \\ Иманалиев Магомед Расулович \\ Д.м.н., профессор, Дагестанский государственный \\ медицинский университет \\ Магомедов Магомед Арсенович \\ Ассистент, Дагестанский государственный \\ медицинский университет
}

Аннотация. Перитонеальные спайки представляют собой важную клиническую проблему в хирургии желудочно-кишечного тракта. Спайки брюшины являются следствием раздражения брюшины инфекцией или хирургической травмой и могут рассматриваться как патологическая часть заживления после любой травмы брюшины, в частности в абдоминальной хирургии. Баланс между отложением фибрина и деградацией имеет решающее значение для определения нормального заживления брюшины или формирования адгезии. Послеоперационные перитонеальные спайки являются основной причиной заболеваемости, приводящей к множественным осложнениям, многие из которых могут проявляться через несколько лет после первичной хирургической процедуры. Помимо острой тонкокишечной непроходимости, перитонеальные спайки могут вызывать тазовые или абдоминальные боли, а также бесплодие. В данной работе авторы рассмотрели эпидемиологию, патогенез и различные профилактические стратегии формирования адгезии. Исследовано несколько профилактических средств против послеоперационных спаек брюшины. Их роль направлена на активизацию фибринолиза, затруднение свертывания крови, уменьшение воспалительной реакции, ингибирование синтеза коллагена или создание барьера между соседними раневыми поверхностями. Их результаты обнадеживают, но большинство из них противоречивы и достигаются в основном на животных моделях. При современном состоянии знаний доклинические или клинические исследования все еще необходимы для оценки эффективности разработки стратегий профилактики послеоперационных перитонеальных спаек, что и обсуждается в этом обзоре.

Ключевые слова: абдоминальная хирургия, лапароскопия, осложнение, адгезиолизис, абдоминальная боль, спайки.

ющих 10 лет при состояниях напрямую или, возможно, связанные с спайки, или еще одна операция, которая потенциально может быть затруднена из-за образования спаек; > 20\% от общего числа повторных госпитализаций произошли в течение первого года после первой операции, и 4,5\% повторных госпитализаций были для клея кишечная непроходимость $[1,43]$. Колоректальная хирургия оказалась наиболее важным видом хирургии, которая может вызвать внутрибрюшные спайки [43]. Эта 
операция имеет самое большое общее число эпизодов стационарного лечения, дней пребывания в стационаре, операционное время, и затраты, связанные с перитонеальной адгезивной кишечной непроходимостью [31, 36]. Среди открытых гинекологических вмешательств операция на яичниках имела самый высокий процент, непосредственно связанных со спаечным процессом (7,5 на 100 операций) [6, 20]. Тонкокишечная непроходимость ранней спаечной непроходимости является наиболее распространенным осложнением спаечного процесса в брюшине [36, 37].

Помимо СКН, перитонеальные спайки могут вызывать тазовые или абдоминальные боли, а также бесплодие [19]. Перитонеальные спайки могут также продлить время, необходимое для получения доступа к брюшной полости при последующих операциях [3] и могут увеличить риск повреждения кишечника во время последующих операций [10]. Остается спорным вопрос о роли спаек брюшины при болях в животе. Спайки были вовлечены в качестве значимой причины хронической тазовой боли, и их хирургический лизис был предложен в качестве терапевтической модальности выбора [20]. Однако хроническая тазовая боль является одной из самых распространенных гинекологических жалоб и все же остается загадкой. Сравнение пациентов с хронической тазовой болью и пациенток с бессимптомным бесплодием не выявило достоверной разницы в плотности или расположении спаек [22].

\section{Патофизиология послеоперашионной алгезии брюшины}

Первые спайки брюшины были описаны при посмертном обследовании больного с перитонеальным туберкулезом в 1836 году. Для объяснения этого открытия в 1849 году было высказано предположение, что коагулированные лимфатические сосуды могут превращаться в фибринозные спайки $[40,52]$. До сих пор точная патофизиология перитонеальных спаек оставалась неуловимой. Несмотря на многочисленные клинические и экспериментальные исследования, патофизиология перитонеальных спаек остается спорной. Помимо нормальной регенерации брюшины, процесс формирования послеоперационной адгезии брюшины может рассматриваться как патологическая часть заживления после любой травмы брюшины, особенно при абдоминальной хирургии [7, 21, 27]. Баланс между отложением фибрина и деградацией имеет решающее значение для определения нормального заживления брюшины или формирования адгезии. Если фибрин полностью деградирован, может произойти нормальное заживление брюшины. В отличие от этого, не полностью деградированный фибрин может служить в качестве каркаса для фибробластов и капилля- ров в процессе роста с образованием перитонеальных спаек.

Повреждение брюшины, вызванное операцией, инфекцией или раздражением, инициирует воспаление с фибринозным экссудатом и образованием фибрина [1, $6,11,30]$. Фибрин является результатом активации коагуляционного каскада, который активируется в брюшной полости, что приводит к образованию тромбина, который запускает преобразование фибриногена в фибрин. Однако, вследствие активации фибринолитической системы, любые внутрибрюшные депозиты фибрина необходимо лизировать. Однако после абдоминальной хирургии равновесие между свертыванием и фибринолизом нарушается в пользу системы свертывания. Таким образом, отложения фибриновых форм являются матрицей для врастания фиброколлагенической ткани. Действительно, фибробласты вторгаются в фибриновый Матрикс, и внеклеточный матрикс (ВМ) вырабатывается и депонируется. Этот ВМ все еще может быть вполне ухудшен проэнзимами металлопротеазы матрицы (ММР). Однако, если этот процесс ингибируется тканевыми ингибиторами ММП, могут образовываться перитонеальные спайки [34]. Как правило, если фибринолиз не происходит в течение 5-7 дней после травмы брюшины, временный фибриновый матрикс сохраняется и постепенно организуется коллаген-секретирующими фибробластами. Этот процесс приводит к образованию перитонеальной адгезии $[8,17,45]$ и росту новых кровеносных сосудов, опосредованному автогенными факторами [12].

Активация фибринолитической системы приводит к превращению плазминогена в плазмин, что весьма эффективно при деградации фибрина в продукты деградации фибрина. Активатор плазминогена тканевого типа (ТПА) и урокиназный плазминоген (УПА) являются активаторами плазминогена. Они экспрессируются в эндотелиальных клетках, мезотелиальных клетках и макрофагах. ТПА, протеаза серина, главный активатор плазминогена и имеет высокое сродство для фибрина. Он связывается со специфическим рецептором, который экспонирует сильный участок связывания плазминогена на поверхности молекулы фибрина. Поэтому в присутствии фибрина резко повышается скорость активации плазминогена, тогда как в отсутствие фибрина ТПА является плохим активатором плазминогена [57]. Это приводит к более высокой активации плазминогена в тех местах, где это необходимо, в то время как системная активация предотвращается. В брюшной полости ТПА отвечает за 95\% активирующей плазминоген активности [15]. УПА одинаково эффективен при деградации фибрина [57], но его гораздо более низкое сродство к фибрину приводит к значительно более низкой активирующей плазминоген активности. Помимо активации плазминогена, УПА может играть важную роль в ремоделировании тканей [42]. 
Активация плазминогена затруднена ингибитором активации плазминогена ИАП-1 и ИАП-2 через образование неактивных комплексов. Наиболее мощным ингибитором ТПА и УПА является гликопротеин ИАП-1. ИАП-2 менее эффективен в противодействии активаторам плазминогена. Вероятно, он играет определенную роль В восстановлении тканей брюшины [42]. ИАП-1, и ИАП-2 продуцируются эндотелиальными клетками, мезотелиальными клетками, моноцитами, макрофагами и фибробластами. Были определены другие ингибиторы активатора плазминогена ИАП-3. Несколько ингибиторов протеазы, таких как a2-макроглобулин, al-антитрипсин и а2-антиплазмин, ингибируют плазмин непосредственно. Однако их роль в перитонеальном фибринолизе четко не определена [15]. Баланс между активаторами плазминогена и ингибиторами плазминогена имеет решающее значение для определения нормального заживления или образования адгезии. 1). Поэтому считается, что ИАП-1 является важным фактором в развитии спаек и высокие концентрации ИАП обнаружены в спаечной и перитонеальной тканях пациентов с обширными спаечными процессами [15, 28, 42]. Также было установлено, что ботулинический токсин типа A (BoNT-A) нарушает связь между клетками на эпителиальном барьере, связывая молекулы эпителия, и обладает противовоспалительной эффективностью [2]. BoNT-A представляет собой нейротоксин с нейротоксической структурой белка, продуцируемый бактериями Clostridium botulinum. BoNT-A демонстрирует свою противовоспалительную эффективность через макрофаги, которые являются основными клетками иммунной системы [48]. Исследование показало, чтоприменение внутрибрюшинно ВоТ-А вызывает значительное снижение количества фибробластов, уменьшение количества фибробластов может быть причиной снижения плотности коллагена [48].

\section{Профи^актика}

Исследовано несколько профилактических средств против послеоперационных спаек брюшины. Их роль заключается в активации фибринолиза, замедлении свертывания крови, уменьшении воспалительной реакции, ингибировании синтеза коллагена или создании барьера между соседними раневыми поверхностями. Эти стратегии профилактики можно разделить на четыре категории: общие принципы, хирургические методы, механические барьеры и химические агенты $[9,21]$.

\section{Обшие приншипы и хирургические техники}

Некоторые основные принципы должны соблюдаться во время всех абдоминальных хирургических процедур. Эти принципы близки к «Халстедовским принципам « (W.S. Halsted 1852-1922), первому хирургу, который признал важность этих мер [39]. Повреждения брюшины следует избегать путем тщательного обращения с тканью, тщательного гемостаза, непрерывного орошения и предотвращения ненужного высыхания, неэффективного использования инородных тел, а также сшивания или зажима ткани. Также рекомендуется использовать тонкие и биосовместимые шовные материалы, атравматичные инструменты и бескрахмальные перчатки. Крахмальные перчатки являются существенным фактором риска возникновения послеоперационных спаек. Инородные тела наиболее часто встречаются в послеоперационных спайках: поверхностные порошки из хирургических перчаток; ворсинки из пакетов, драпировок или халатов; древесные волокна из одноразовых бумажных изделий; и шовные материалы. Однако последние данные свидетельствуют о том, что при отсутствии дополнительного повреждения брюшины инородные тела являются нечастой причиной индукции адгезии [22]. Ordonez et. al. [51] провели оценку влияния тренировки на формирование послеоперационной адгезии на модели кролика. Тренировочный эффект оценивали по длительности операции и количеству кровотечений. Это исследование показало, что существует значительное влияние опыта на продолжительность операции. С опытом, продолжительность операции прогрессивно уменьшает, и послеоперационные спайки также уменьшают в размере, цепкости, типе и полном счете. Согласно этим выводам, хирургическая подготовка и соблюдение некоторых основных принципов («Халстедские принципы») имеют важное значение для профилактики адгезии.

Некоторые интраоперационные методы, такие как предотвращение ненужного рассечения брюшины или предотвращение закрытия брюшины, должны применяться. Многие экспериментальные исследования показали, что незакрытие брюшины связано со снижением образования перитонеальной адгезии [5, 51]. Тем не менее, некоторые исследования не показали никаких различий [60] или даже снижение адгезии брюшины [61] с закрытием брюшины. Однако трансплантация или ушивание дефектов брюшины может приводить к увеличению ишемии брюшины, деваскуляризации и некрозу, предрасполагая этот участок к снижению фибринолитической активности и увеличению образования адгезии [51].

Кроме того, хирургическая травма должна быть максимально уменьшена. Хирургический подход (открытый или лапароскопический) может играть важную роль в развитии спаечного процесса. В большинстве абдоминальных процедур лапароскопический подход связан со значительно более низкой частотой послеоперационных перитонеальных спаек или связанных с адгезией повторных госпитализаций. 
Некоторые исследования не показали разницы между обоими хирургическими подходами. Сообщается о роли СО2 в формировании адгезии после лапароскопической операции [51, 62].

Во время лапароскопической операции пневмоперитонеум CO2 сам по себе оказывает реальное воздействие на спаечный процесс в брюшной полости. Было показано, что образование адгезии увеличивается с увеличением продолжительности пневмоперитонеума СО2 и давления инсуффляции [51, 62]. Действительно, длительная лапароскопическая операция требует деятельной длительности и большого объема газовых инсуффляций, что вызывает опасения по поводу неблагоприятных последствий длительных газовых инсуффляций [62]. Стандартным СО2, используемым в современной лапароскопической практике, является холодный сухой СО2 который не физиологичен для нормальных условий брюшной полости [51]. Многие исследования показали, что кратковременная лапароскопия, < 3 ч, с холодной сухой инсуффляцией $\mathrm{CO} 2$ может вызвать перитонеальные изменения и привести к многочисленным неблагоприятным исходам, включая формирование послеоперационной перитонеальной адгезии [51, 62]. Было сообщено, что преимущества нагретой увлажненной инсуффляций $\mathrm{CO} 2\left(37^{\circ} \mathrm{C}\right.$ и 95\% относительной влажности, физиологические условия) включают меньшую гипотермию, меньшие послеоперационные боли, сокращенное пребывание в послеоперационном периоде, лучшее выздоровление, меньшее распространение и рост опухоли [62] и меньшее образование адгезии $[14,18]$. Кроме того, Molinas et. al. [49] было продемонстрировано, что пневмоперитонеум СО2 увеличивает послеоперационные спайки брюшины в зависимости от времени и давления, и что это увеличение уменьшается за счет добавления 2-4\% кислорода, что предполагает перитонеальную гипоксию в качестве движущего механизма. Предполагается, что при снижении фибринолитической активности процесс формирования адгезии уже не зависит от хирургического подхода, а развивается самостоятельно.

Механические барьеры: жидкие или твердые механические барьеры могут препятствовать образованию послеоперационной перитонеальной адгезии, сохраняя отдельные поверхности брюшины в течение 5-7 дней, необходимых для перитонеальной реэпителизации. Они предотвращают контакт между поврежденными серозными поверхностями в течение первых нескольких критических дней. Идеальный барьер должен быть биодеградируемым, безопасным, невоспалительным, не иммуногенным, сохраняться в течение критической фазы ре-мезотелизации, оставаться на месте без швов или скоб, оставаться активным в присутствии крови и быстро и легко наноситься [53]. Кроме того, он не дол- жен мешать заживлению, способствовать инфицированию или вызывать спайки. Барьеры в настоящее время считаются наиболее полезными адъюнктами, которые могут уменьшить образование послеоперационной перитонеальной адгезии. Различные твердые или жидкие барьерные агенты были испытаны экспериментально и в клинических испытаниях.

Для предотвращения адгезии использовались такие жидкости, как кристаллоиды, декстран, гиалуроновая кислота, сшитая гиалуроновая кислота и икодекстрин. Они отделяют поврежденные поверхности «гидрофлатацией», но их эффективность вызывает споры. Кристаллоиды, такие как физиологический раствор и лактат Рингера, используются в больших количествах, но они быстро всасываются. Наиболее часто применяемым гипертоническим раствором был 32\% декстран 70, но от него отказались из-за серьезных осложнений [51]. Другие жидкие барьеры, которые имеют преимущество более длительного пребывания в брюшной полости, такие как гиалуроновая кислота (Sepracoat ${ }^{\circledR}$, Genzyme Corporation, Cambridge, MA, United States), кросс-связанная гиалуроновая кислота (Intergel Hyalobarrier gel; Baxter, Pisa, Italy) и икодекстрин (Adept, Baxter Healthcare Corporation, Deerfield, IL, United States) показали многообещающие результаты в экспериментальных и клинических исследованиях [51]. Brown et. al. [26] продемонстрировали, что адепт является безопасным и эффективным агентом снижения адгезии при лапароскопии.

Существуют нерассасывающиеся и био-рассасывающиеся пленки, гели или твердые мембраны. Наиболее часто используемыми механическими барьерами являются окисленная регенерированная целлюлоза (Interceed $\left.{ }^{\circledR}\right)$, расширенный политетрафторэтилен, гиалуроновая кислота-карбоксиметилцеллюлоза (Seprafilm) и полиэтиленгликоль. Preclude не поддается разложению и требует проведения второй операции по удалению. Наиболее широко изученными биоабсорбируемыми пленками являются Сепрафильм и Интеркид. Сепрафильм всасывается в течение 7 дней и выводится из организма в течение 28 дней [51]. Проспективные рандомизированные контролируемые исследования показали эффективность Сепрафильма в снижении частоты и степени послеоперационных спаек [23]. Однако Сепрафильм может вызвать значительное нарушение анастомозов и не должен применяться в случаях анастомоза [23]. Другие экспериментальные исследования показали, что покрытие поражений париетальной брюшины микрохирургически применяемыми аутологичными перитонеальными трансплантатами может полностью предотвратить формирование выраженной перитонеальной адгезии. Однако преимущество синтетического барьера заключается в том, что материал не требует хирургического вмешательства и может быть разрезан 
по размеру вне брюшной полости, а затем нанесен без швов [46].

Химические вещества. Химические вещества вообще предотвращают организацию упорствуя фибрина, фибробластическим ингибитированием пролиферации. Для ингибирования этой пролиферации используется много средств, таких как нестероидные противовоспалительные препараты (НПВП), кортикостероиды, блокаторы кальциевых каналов, антагонисты гистамина, антибиотики, фибринолитические агенты, антикоагулянты, антиоксиданты, гормоны, витамины, колхицины и селективные иммуносупрессоры. НПВП уменьшают спаечный процесс в брюшине у некоторых животных моделей путем ингибирования синтеза простагландина и тромбоксана. Они снижают проницаемость сосудов, ингибиторы плазмина, агрегацию тромбоцитов и свертывание крови, а также усиливают функцию макрофагов [51]. Rodgers et. al. [59] показали, что послеоперационное введение противовоспалительных препаратов в место травмы уменьшало образование послеоперационных спаек на двух моделях животных. Модель крысы была использована для исследования эффективности нимесулида, селективного ингибитора циклооксигеназы-2, в предотвращении образования адгезии. Данное исследование показало, что предоперационное внутримышечное или послеоперационное интраперитонеальное введение нимесулида в место повреждения снижало формирование послеоперационной адгезии у данной модели крыс [38]. Как правило, некоторые противовоспалительные препараты могут быть эффективными в предотвращении спаек, но нет никаких клинических значимых доказательств из любого опубликованного исследования, чтобы рекомендовать их использование у людей для этой цели, и несколько побочных эффектов все еще должны быть установлены [50].

Кортикостероидная терапия снижает проницаемость сосудов и высвобождение цитокинов и хемотаксических факторов, а также снижает образование перитонеальной адгезии в некоторых моделях животных [46]. Однако кортикостероиды имеют побочные эффекты, такие как иммуносупрессия и замедленное заживление ран [51]. Kirdak et. al. [44] исследовали эффективность различных доз метшшреднизолона в профилактике экспериментально индуцированных перитонеальных спаек у крыс. Они обнаружили, что не было никакой разницы в эффективности различных доз метилпреднизолона, вводимых местно, в предотвращении образования перитонеальной адгезии, и, кроме того, стероиды не предотвращали развитие перитонеальной адгезии [46]. В животных моделях эти гормоны могут предотвращать образование адгезии, но некоторые исследования не подтвердили эту эффективность у человека [51].
Было сообщено, что прогестерон оказывает противовоспалительное и иммуносупрессивное действие, а также может предотвращать образование адгезии [56]. Однако, показано, что в целом не было достоверной разницы в частоте образования адгезии между кроликами, получавшими прогестерон, и контрольными кроликами. Они выявили благоприятное влияние прогестерона на снижение только незначительного адгезионного образования, образующегося после незначительного повреждения брюшины. Кроме того, было показано, что ни эстроген, ни гонадотропин-рилизинг гормон не предотвращали образование адгезии, но было меньше спаек, образованных в эстроген-обработанных, чем у необработанных животных [51].

Об использовании антикоагулянтов для предотвращения образования спаек брюшины с энтузиазмом сообщается в литературе [51]. Было использовано много молекул, таких как гепарин или дикумарол, которые предотвращают адгезию путем увеличения фибринолиза за счет активности серинэстеразы [38]. Гепарин является наиболее широко исследуемым антикоагулянтом, применяемым для профилактики спаечных процессов. Однако его эффективность в снижении образования адгезии, независимо от того, вводится ли он самостоятельно или в комбинации с межклеточным барьером, не была продемонстрирована в клинических испытаниях [50].

Фибринолитические агенты, такие как рекомбинантный ТПА, при местном применении уменьшают спайки в моделях животных [38]. Однако эти фибринолитические агенты могут вызывать геморрагические осложнения [50]. Три различных препарата: ТПА (Actilyse ${ }^{\circledR}$ ), активированный дротрекогин Альфа, которые влияют на процесс коагуляции на различных стадиях, были изучены для их эффективности в предотвращении образования внутрибрюшинной адгезии у крыс [59]. Все три средства были эффективны в предотвращении спаек по сравнению с контрольной группой. Тем не менее, активированный дротрекогин Альфа казался наиболее эффективным, за исключением рассмотрения клинической применимости, и в этом случае фондапаринукс, казалось, предлагал наибольшее преимущество [23]. Однако дальнейшие исследования показали, что все эти подходы могут иметь лишь ограниченный успех, сдерживаться недостаточной безопасностью, эффективностью и многими побочными эффектами без устранения проблемы формирования послеоперационной перитонеальной адгезии [51].

Некоторые антибиотики обычно используются для профилактики послеоперационных инфекций и образования адгезии. Меньшая инфицированность брюшины может привести к меньшему образованию спаечного процесса в брюшине. Установлено, что линезолид 
снижает внутрибрюшинное адгезионное образование [18]. Однако другие исследования показали, что внутрибрюшное применение само по себе вызывает образование адгезии [55]. Sortini et. al. [58] показали, что антибиотики приводили к большему образованию адгезии по шкале Zuhlke по сравнению с физиологическим раствором, тогда как между антисептиками и физиологическим раствором не наблюдалось никакой разницы. Действительно, было показано, что антибиотики в растворах для внутрибрюшинного орошения увеличивают образование перитонеальной адгезии на моделях крыс, и поэтому они не рекомендуются в качестве единого агента для предотвращения адгезии [58].

Витамин Е является наиболее изученным витамином в профилактике адгезии. Исследования in vitro показали, что витамин Е оказывает антиоксидантное, противовоспалительное, антикоагулянтное и антифибробластическое действие, а также снижает выработку коллагена. Некоторыми авторами было установлено, что он эффективен для снижения адгезионного образования [32, 33, 54]. Corrales et. al. [32] показали, что витамин E, вводимый внутрибрюшинно, так же эффективен, как и карбоксиметилцеллюлозная мембрана в предотвращении послеоперационных спаек. В отличие от этого, аналогичный эффект не был достигнут после внутримышечного введения [33]. Было обнаружено значительное различие между внутрибрюшинным и внутримышечным введением витамина E [54]. Таким образом, внутрибрюшинное введение витамина Е может быть рекомендовано для предотвращения образования адгезии. Однако, согласно нашему обзору литературы, не было ни одного исследования на людях, которые рекомендовали бы применение витамина Е для профилактики послеоперационной адгезии.

Одно из исследований было проведено с целью выяснения влияния различных концентраций метиленового синего на процесс формирования перитонеальной адгезии и определения его минимальной дозы, которая может эффективно предотвращать образование таких спаек на модели крыс [35]. Можно сделать вывод, что 1\% метиленовый синий обладает лучшим антиадгезионным потенциалом [47]. Если метиленовый синий предотвращает спаечный процесс в брюшине, то он может вызвать значительное снижение давления разрыва анастомоза на ранней стадии раневого процесса за счет его транзиторного ингибирующего действия на пути оксида азота [35].

Спайки являются результатом воспалительной реакции на повреждение тканей в брюшинном пространстве. Хотя механизм неясен, местные анестетики, как сообщается, имеют некоторые противовоспалительные эффекты, как показано в некоторых исследованиях на животных $[16,29,41]$. Эти противовоспалительные эффекты связаны с ингибированием нейтрофилов. Также было показано, что местные анестетики активируют фибринолитическую систему, снижают концентрацию фактора VIII, плазминогена и а2-антиплазмина, а также ингибируют агрегацию тромбоцитов [41]. Таким образом, помимо ускоряющего действия смеси 2,5\% лидокаина и 2,5\% прилокаина в процессе заживления ран, некоторые исследования показали, что внутрибрюшинный лидокаин и прилокаин ингибируют образование послеоперационных перитонеальных спаек без ущерба для заживления ран на модели бактериального перитонита у крыс [24].

\section{Зак^ючение}

Послеоперационные перитонеальные спайки являются серьезной проблемой здравоохранения со значительным экономическим эффектом. По-видимому, фибринолиз является ключевым фактором в определении патогенеза образования адгезии и в ее профилактике. Было проведено несколько исследований по этой проблеме. Их результаты обнадеживают, но большинство из них противоречивы и были проведены на животных моделях. До тех пор, пока не будут получены дополнительные результаты будущих клинических исследований, только тщательная хирургия может быть рекомендована для снижения ненужной заболеваемости и смертности от этих неблагоприятных последствий хирургии. При современном состоянии знаний доклинические или клинические исследования все еще необходимы для оценки эффективности нескольких предложенных стратегий профилактики послеоперационных перитонеальных спаек.

\section{ЛИТЕРАТУРА}

1. Алмабаев Ы.А, Кыжыров Ж. Н., Акжолова Я. Д., Фахрадиев И. Р. К вопросу профилактики спаечного процесса (обзор литературы). Наука и мир 2016; 3: $70-72$.

2. Артеменко А. Р., Куренков А. Л. Ботулинический токсин: вчера, сегодня, завтра. Нервно-мышечные болезни. 2013; 2: 6-18.

3. Ахметзянов Ф. Ш., Егоров В. И., Анхимова Л. Е. Спаечный процесс как проблема абдоминальной оперативной онкологии. Сибирский онкологический журнал. 2018; 17 (2): 95-103.

4. Аюшинова Н. И., Шурыгин И. А., Шурыгин М. Г., Панасюк И. А. Современные подходы к профилактике спаечного процесса в брюшной полости. Сибирский медицинский журнал. 2011; 6: 16-20. 
5. Аюшинова Н. И., Шурыгина И. А., Григорьев Е. Г., Чепурных Е. Е., Шурыгин М. Г. Оценка выраженности спаечного процесса брюшной полости (клиническое исследование). Современные проблемы науки и образования. 2018; 6; [Электронный ресурc]. URL: http://science-education.ru/ru/article/view?id=28209

6. Беженарь В.Ф., Цыпурдеева А. А., Байлюк Е. Н. Спаечная болезнь органов малого таза у гинекологических больных: от патогенеза к практике. Онкогинекология. 2014; 4: 68-74.

7. Бойко В. В., Евтушенко Д. А. Способ профилактики спайкообразования у ранее оперированных больных на органах брюшной полости. Инновации в науке. 2013; 25: 177-181.

8. Бойко В. В. Генетические факторы патогенеза спаечной болезни брюшины. Вестник Авиценны. 2015; 2 (63): 25 -30.

9. Гаспаров А. С., Дубинская Е. Д. Тазовые перитонеальные спайки: этиология, патогенез, диагностика, профилактика. М.: 000 «Медицинское информационное агентство», 2013; 168.

10. Китаев А. В., Айрапетян А. Т., Турлай Д. М. Спаечная болезнь брюшины в эксперименте. Профилактика и лечение. Колопроктология. 2016; S1: 118а.

11. Кондратович Л. М. Основы понимания формирования спаечного процесса в брюшной полости. Интраоперационная профилактика противоспаечными барьерными препаратами (обзор литературы). Вестник новых медицинских технологий. 2014; 21:3: 169-173.

12. Костырной А. В., Гройзик К. Л., Мустафаева С. Р. Спаечная болезнь брюшины: настоящее и будущее проблемы. Таврический медико-биологический вестник. 2013; 16: 1-3 (61): 262-267.

13. Назаренко А. А., Акимов В. П. Преодоление адгезиогенеза. Медицинский вестник юга России. 2014; 4: 15-18.

14. Насретдинов И. Г., Ишкинин Р.Э., Гарипов И. И. Противоспаечные способы обработки брюшной полости. Новая наука: проблемы и перспективы. 2016; (4-2): 30-33.

15. Литвинов Р. И. Молекулярные механизмы и клиническое значение фибринолиза. Казанский медицинский журнал. 2013; 94(5): 711-718.

16. Овечкин А. М. Клиническая фармакология местных анестетиков: классические представления и новые перспективы применения в интенсивной терапии. Регионарная анестезия и лечение острой боли Том VII № 3 2013; 6-15.

17. Осомбаев М. Ш., Жакипбеков С. Т., Джекшенов М. Д. Спаечная болезнь брюшной полости (обзор литературы). Вестник Кыргызско-Российского славянского университета. 2016; 16: 3: 78-80.

18. Самарцев В. А., Кузнецова М. В., Гаврилов В. А., Кузнецова М. П., Паршаков А. А. Противоспаечные барьеры в абдоминальной хирургии: современное состояние проблемы. Пермский медицинский журнал 2017; 34 (2): 87-93.

19. Сидоренко В. Н., Хартанович Т. А. К вопросу о патогенезе и профилактике спаечного процесса органов брюшной полости при оперативных вмешательствах. Военная медицина. 2011; 1: 140-144.

20. Тихомиров А. Л., Манухин И. Б., Казенашев В. В., Манухина Е. И., Юдина Т. А. Профилактика спаечного процесса и его осложнений в оперативной гинекологии. Российский вестник акушера-гинеколога 5, 2016: 100-105.

21. Филенко Б. П., Земляной В. П., Борсак И. И., Иванов А. С. Спаечная болезнь: профилактика и лечение. СПб.: СЗГМУ им. ИИ Мечникова. $2013 ; 171$.

22. Arung W., Meurisse M., Detry 0. Pathophysiology and prevention of postoperative peritoneal adhesions. World J Gastroenterol $2011 ; 41$ (17): $4545-4553$.

23. Beck D. E., Cohen Z., Fleshman J.W., Kaufman H.S., van Goor H., Wolff B. G. A prospective, randomized, multicenter, controlled study of the safety of Seprafilm adhesion barrier in abdominopelvic surgery of the intestine. Dis Colon Rectum 2003; 46: 1310-1319.

24. Blumental S., Borgeat A., Pasch T. Ropivacaine decreases inflammation in experimental endotoxin-induced lung injury. Anesthesiology. $2006 ; 104: 961-969$.

25. Brochhausen C. Current strategies and future perspectives for intraperitoneal adhesion prevention. J Gastrointest Surg. 2012; 16: 1256-1274.

26. Brown C. B., Luciano A. A., Martin D., Peers E., Scrimgeour A., diZerega G.S. Adept (icodextrin $4 \%$ solution) reduces adhesions after laparoscopic surgery for adhesiolysis: a doubleblind, randomized, controlled study. Fertil Steril 2007; 88: 1413-1426.

27. Buckman R. F., Woods M., Sargent L., Gervin A. S. A unifying pathogenetic mechanism in the etiology of intraperitoneal adhesions. J Surg Res 1976; $20: 1: 1-5$.

28. Bukata V., Chornomydz A. Prevention of peritoneal adhesions: from surgery to farmacology. Norwegian Journal of development of the International Science. 2019; 29: 34-40.

29. Cassuto J., Sinclair R., Bonderovic M. Anti-inflammatory properties of local anesthetics and their present and potential clinical implications. Acta Anaesth.Scand. 2006; 50: 265-282.

30. Coccolini F., Ansaloni L., Manfredi R. et al. Peritoneal adhesion index (PAI): proposal of a score for the "ignored iceberg" of medicine and surgery. World J. Emerg. Surg. 2013; 8(1); [Электронный ресурс]. URL: https://wjes.biomedcentral.com/articles/10.1186/1749-7922-8-6

31. Coleman M. G., Mc Lain A. D., Moran A. B. Impact of previous surgery on time taken for incisions and division of adhesions during laparotomy. Dis. Colon. Rectum. 2000; 43: 1297-1299.

32. Corrales F, Corrales M, Schirmer CC. Pre-venting intraperitoneal adhesions with vitamin E and sodium hyaluronate/carboxymethylcellulose: a com-parative study in rats. Acta Cir Bras. 2008; 23: 36-41.

33. de la Portilla F, Ynfante I, Bejarano D, Conde J, Fernбndez A, Ortega JM, Carranza G. Prevention of peritoneal adhesions by intraperitoneal administration of vitamin E: an experimental study in rats. Dis Colon Rectum. 2004; 47: 2157-2161.

34. Demir Weusten A. Y., Groothuis P. G., Dunselman G. A., de Goeij A. F., Arends J. W., Evers J. L. Morphological changes in mesothelial cells induced by shed menstrual endometrium in vitro are not primarily due to apoptosis or necrosis. Hum Reprod. 2000; 15: 1462-1468.

35. Dinc S, Ozaslan C, Kuru B, Karaca S, Ustun H, Alagol H, Renda N, Oz M. Methylene blue prevents surgery-induced peritoneal adhesions but impairs the early phase of anastomotic wound healing. Can J Surg. 2006; 49: 321-328.

36. Dubuisson J., Botchorishvili R., Perrette S., Bourdel N., Jardon K., Rabischong B., Canis M., Mage G. Incidence of intraabdominal adhesions in a continuous series of 1000 laparoscopic procedures. Am. J. Obstet. Gynecol. 2010; 203(2); 111.e1-111.e3. 
37. Gonzalez-Quintero VH, Cruz-Pachano FE. Preventing adhesions in obstetric and gynecologic surgical procedures. Rev 0bst Gyn. 2009; 2:1:38-45.

38. Guvenal T., Cetin A., Ozdemir H., Yanar 0., Kaya T. Prevention of postoperative adhesion formation in rat uterine horn model by nimesulide: a selective COX2 inhibitor. Hum Reprod 2001; 16: 1732-1735.

39. Heuer G. J., Miller R. T., Matas R. In memoriam William Steward Halsted: 1852-1922. Arch Surg 1925; 10: 293-305.

40. Hodgkin T. Lectures on the morbid anatomy of the serous and mucous membranes. London: Simpkin Marshall and C0, 1836; 141.

41. Hollmann M., Durieux M. Local anesthetics and the inflammatore response: a new therapeutic indication? Anesthesiology. 2000; $93:$ 858-875.

42. Howell N., Senanayake E., Freemantle N., Pagano D. Putting the record straight on aprotinin as safe and effective: results from a mixed treatment meta-analysis of trials of aprotinin. J. Thorac. Cardiovasc. Surg. 2013; 145: 234-240.

43. Imudia A. N., Kumar S., Saed G. M., Diamond M. P. Pathogenesis of Intra-abdominal and pelvic adhesion development. Semin. Reprod. Med. $2008 ; 26$ (4): $289-297$.

44. Kirdak T., Uysal E., Korun N. Assessment of effectiveness of different doses of methylprednisolone on intraabdominal adhesion prevention. Ulus Travma Acil Cerrahi Derg 2008; 14: 188-191.

45. Lee YCG, Teixeira LR, Devin CJ. Transforming growth factor-b2 induces pleurodesis significantly faster than talc. Am J Respir Cri Care Med. 2001 ; 163: 640-644.

46. Liakakos T., Thomakos N., Fine P. M., Dervenis C., Young R. L. Peritoneal adhesions: etiology, pathophysiology, and clinical signifiance. Recent advances in prevention and management. Dig Surg 2001; 18: 260-273.

47. Mahdy T., Mohamed G., Elhawary A. Effect of methylene blue on intra-abdominal adhesion for-mation in rats. Int J Surg. 2008; 6: 452-455.

48. Marinelli S., Vacca V., Ricordy R. et al. The analgesic effect on neuropathic pain of retrogradely transported botulinum neurotoxin A involves Schwann cells and astrocytes. PLoS One. 2012; 7(10): e47977.

49. Molinas C. R., Mynbaev 0., Pauwels A., Novak P., Koninckx P. R. Peritoneal mesothelial hypoxia during pneumoperitoneum is a cofactor in adhesion formation in a laparoscopic mouse model. Fertil Steril 2001; 76: 560-567.

50. Nappi C., Di Spiezio Sardo A., Greco E., Guida M., Bettocchi S., Bifulco G. Prevention of adhesions in gynaecological endoscopy. Hum Reprod Update 2007; 13: 379-394.

51. Ordocez J. L., Domнnguez J., Evrard V., Koninckx P. R. The effect of training and duration of surgery on adhesion formation in the rabbit model. Hum Reprod 1997; 12: 2654-2657.

52. Rokitansky C. A. Manual of pathological anatomy The abdominal viscera. London: Sydenham Society, 1849; 39.

53. Rout U. K., Diamond M. P. Role of plasminogen activators during healing after uterine serosal lesioning in the rat. Fertil Steril 2003; 79: 138-145.

54. Sanfilippo J. S., Booth R. J., Burns C. D. Effect of vitamin E on adhesion formation. J Reprod Med. 1995; 40: 278-282.

55. Seriau L., Lauretta A., Infantino A. Abdominal Adhesions: From formation to prevention. Soc Ital Chir ColoRettale. 2013; 35: 289-300.

56. Schipper E, Valle RF, Nezhat C.Intrauterine adhesions: hysteroscopic evaluation and treatment. Website: hhtp://laparoscopy. blogs.com/prevention _ management_3/2010/11

57. Singh N. K., Gupta A., Behera D. R., Dash D. Elevated plasminogen activator inhibitor type-1 (PAl-1) as contributing factor in pathogenesis of hypercoagulable state in antiphospholipid syndrome. Rheumatol. Int. 2013; 33: 2331-2336.

58. Sortini D, Feo CV, Maravegias K. Role of peritoneal lavage in adhesion formation and survival rate in rats: an experimental study. J Invest Surg. 2006; 19: $291-297$.

59. Topal E., Ozturk E., Sen G., Yerci 0., Yilmazlar T. A comparison of three fibrinolytic agents in prevention of intraabdominal adhesions. Acta Chir Belg 2010; 110: 71-75.

60. Viana Ade T., Daud F.V., Bonizzia A., Barros P. H., Gouvka E. S. Comparative study between parietal peritoneum suture and nonsuture in midline laparotomies in rats. Acta Cir Bras 2008; 23: 348-351.

61. Whitfield R. R., Stills H. F., Huls H. R., Crouch J. M., Hurd W. W. Effects of peritoneal closure and suture material on adhesion formation in a rabbit model. Am J Obstet Gynecol 2007; 197: 644.e1644.e5, 1-3.

62. Yesildaglar N., Koninckx P. R. Adhesion formation in intubated rabbits increases with high insufflation pressure during endoscopic surgery. Hum Reprod 2000; 15: 687-691.

( ) Магомедов Мухума Магомедович ( muxuma@mail.ru ), Иманалиев Магомед Расулович, Магомедов Магомед Арсенович.

Журнал «Современная наука: актуальные проблемы теории и практики» 